\title{
Social capital and workplace bullying
}

\author{
Patricia Pihl ${ }^{\mathrm{a}, *}$, Karen Albertsen ${ }^{\mathrm{b}}$, Annie $\operatorname{Hogh}^{\mathrm{c}}$ and Lars Peter Sønderbo Andersen ${ }^{\mathrm{a}}$ \\ ${ }^{a}$ Danish Ramazzini Center, Department of Occupational Medicine, Herning, Denmark \\ ${ }^{\mathrm{b}}$ Team Working Life Aps, Valby, Denmark \\ ${ }^{\mathrm{c}}$ Department of Psychology, University of Copenhagen, Denmark
}

Received 13 May 2016

Accepted 4 December 2016

\begin{abstract}
.
BACKGROUND: Workplace bullying is a serious stressor with devastating short- and long-term consequences. The concept of organizational social capital may provide insights into the interactional and communicative dynamics of the bullying process and opportunities for prevention.

OBJECTIVE: This study aimed to explore the association between organizational social capital and being a target or observer of workplace bullying.

METHODS: Based on self-reported cross-sectional data from a large representative sample of the Danish working population $(n=10.037)$, logistic regression analyses were conducted to explore at the individual level the associations between vertical and horizontal organizational social capital with being a target or observer of workplace bullying.

RESULTS: In the fully adjusted models, low organizational social capital (vertical and horizontal) was associated with significantly increased odds ratios of both self-labelled (vertical: $\mathrm{OR}=3.25 ; \mathrm{CI}=2.34-4.51$; horizontal: $\mathrm{OR}=3.17 ; \mathrm{CI}=2.41-4.18$ ) and observed workplace bullying (vertical: $\mathrm{OR}=2.09 ; \mathrm{CI}=1.70-2.56$; horizontal: $\mathrm{OR}=1.60 ; \mathrm{CI}=1.35-1.89$ ), when compared with high organizational social capital.

CONCLUSIONS: This study supports that characteristics of the psychosocial work environment are of importance in the development of workplace bullying, and provides focus on the importance of self-reported organizational social capital.
\end{abstract}

Keywords: Work environment, observers of bullying, targets of bullying, organizational social capital, Danish Work Environment Cohort Study

\section{Introduction}

Over the past 30-40 years there has been an increased focus on bullying in the workplace, both politically and in terms of research. This has largely been due to an increased awareness of the many serious short and long term consequences that have been associated with exposure to bullying [1]. In Denmark, bullying in the workplace is explicitly addressed in both the Working Environment Act [2] and the Ordinance on the performance of work [3]. These laws state that the employer must ensure that working

\footnotetext{
*Address for correspondence: Patricia Pihl, Danish Ramazzini Center, Department of Occupational Medicine, Gl. Landevej 61, 7400 Herning, Denmark. Tel.: +45 7843 3553; E-mail: patricia314hl@gmail.com.
}

conditions are safe and healthy and that it must be ensured that performance of work does not involve a risk to physical or psychological health as a result of bullying, including sexual harassment. The Danish Work Environment Authority provides guidelines for the prevention and management of bullying in the workplace, underlining that bullying is not an individual, but a workplace issue [4]. Hence, it is emphasized that management should express clear views about bullying and harassment and that the organization should, for example, outline clear policies regarding prevention and potential handling of bullying and sexual harassment. The Danish Work Environment Authority may impose injunctions on an organisation, ordering guidance or specific action, if they assess serious problems in the work environment, 
including the presence of bullying [4]. Studies on the consequences of workplace bullying have shown that targets of bullying show higher physiological stress responses (as measured by saliva cortisol) and more symptoms of somatization, depression, anxiety, and negative affect than non-bullied controls [5] and are more likely to experience sleep disturbances [6] and lower sleep quality than individuals who are non-bullied [7]. Longitudinal studies have shown that exposure to bullying in the workplace may have longterm mental health effects up to 5 years after exposure [8], including higher risk of cardiovascular disease, depressive symptoms [9], depression [10], anxiety disorders, persistent somatic symptoms and suicidal ideation [10,11] and long-term stress reactions [12]. Research on the consequences of exposure to bullying in the workplace have further shown increased rates of sickness absence among targets of bullying i.e. $[13,14]$ and greater risk of exclusion from the workplace and from working life itself [15]. Thus, there is plenty of documentation of the negative psychosocial as well as health consequences of bullying, and there is a need to prevent and manage bullying in the workplace. Knowledge about the causes and mechanisms behind bullying is an important step toward this end and it is important to bear in mind that bullying in the workplace is a complex and dynamic phenomenon [1, $16,17]$. Already in the early nineties, Leymann proposed that characteristics of the psychosocial work environment as well as organizational (i.e. how the work is organised, distributed and carried out) and managerial problems are of particular importance to the development of bullying in the workplace [18, 19]. Leymann referred to this as The Work Environment Hypothesis. Previous research has supported the association between bullying and a stressful and negative work environment. Role stressors such as role conflict, role ambiguity and lack of clear goals have been shown to be among the strongest predictors of workplace bullying among factors related to work organization and job design [20-22]. However, recent research has produced mixed results in relation to causality, suggesting reciprocal relationships between role stressors and bullying [20]. Leadership has also consistently been presented as a core element in the bullying process. In particular, leadership styles characterized as tyrannical, autocratic, authoritarian and laissez-faire have been suggested as risk factors of bullying [21-25]. A poor physical work environment, including noisy, crowded, hot or cold and otherwise unpleasant working conditions, has also been associated with increased risks of bullying
[26, 27], while there have been mixed results in relation to high workload and time pressure [25, 26, 28]. Among factors related to organizational climate and culture, bullying has, in both quantitative and qualitative studies, been associated with a poor social climate, poor communication, low trust and inclusiveness as well as experiences of low cooperation and injustice, high levels of interpersonal conflicts and professional and value conflicts [25, 26, 28, 29]. In sum, prior research indicates that features of the psychosocial work environment, and particularly the organizational culture and climate, represent a central, although not exclusive, element of the bullying process.

In recent years, it has also become increasingly apparent that there is more to the psychosocial work environment than descriptive job characteristics, and that the social and relational ties that connect the different employees and their jobs are central features $[30,31]$. One way to conceptualise these ties is by the term of social capital. The concept belongs to a sociological tradition and was originally applied to describe the reproduction, efficiency and cohesiveness of societies [32, 33]. The concept of social capital has lately been applied to several other areas, including organizations and workplaces, as a complementary perspective on the psychosocial work environment [31, 34-36]. There are many definitions of organizational social capital, but typically these centre around the importance of networks and shared norms [37]. Common features of organizational social capital include mutual trust, organizational justice and fairness as well as the ability to cooperate or collaborate towards a collectively, shared goal [34, 35, 38]. Prospective studies have shown that low (self-reported) individual-level ratings of organizational social capital is associated with higher levels of self-reported depression [39], while low organizational social capital at both the individual and work unit level is associated with higher risks of poor health [40]. A 1-year follow-up study furthermore found that increased workplace social capital was associated with lower levels of psychological distress [41].

There are several ways in which organizational social capital and bullying in the workplace could potentially be related. First, high social capital may prevent the development of bullying. High social capital can be seen as a resource that can aid organizations in hard times as a buffer that prevents negative or ambiguous actions to be perceived as bullying [42], or as a buffer that enables the effective resolution 
of conflicts in the bud [38]. High levels of trust can enable confidence in the reasonableness, necessity and fairness of the intentions and decisions of other members of the organization, even when these might seem hard, e.g. downsizing [43]. Effective norms for cooperation can make it easier to prevent and solve conflicts [35]. In organizations characterised by high social capital, relations between employees and leaders show trusting cooperation, common goals and interests and effective conflict resolution [38]. Employees in organizations with high social capital trust each others intentions and decisions, and thereby avoid or minimize speculations of negative intentions behind actions, perceptions of injustice, confidence breaches and mistrust that could lead to suspicions and counteractions, with personal and economic consequences [42]. High organizational social capital can give members of the organization a reason (mediated through trust and collective goal orientation) to set aside personal interests in favour of the long-term goals of the group or organization [34]. Similarly, low social capital could increase the risk of bullying in the workplace, for example, through inadequate conflict resolution. Baillien et al. [26] found that the most important factors associated to the development of bullying in the workplace at the team and organizational level were leadership style, norms and values, communication and social climate. A cross-sectional study on nurses and negative acts in the workplace, showed an inverse relation between horizontal violence (negative acts between coworkers) and peer relations [44]. Høgh et al. [28] furthermore found that targets of bullying in the workplace have lower perceptions of trust, cooperation, conflict resolution and justice in the organization. In a related field, a study found that employees were more likely to be subjected to sexual harassment, if they reported poor workplace relations between management and employees and low co-worker social ties [45]. A recent study found unclear results regarding organizational social capital and social climate and conflicts, with significant associations between organizational social capital and "gossip and slander", but no significant associations between organizational social capital and "conflicts and quarrels." However, according to the researchers the latter result could possibly be due to study design factors [30]. Furthermore, where high organizational social capital can give members of the organization a reason to set aside personal interests in favour of the long-term goals of the group or organization [34] low social capital may be related to micropolitical behavior in the workplace, i.e. acting in order to obtain personal interests and career goals and enhance personal influence, which can be a risk factor for bullying [17, 46-48].

Second, high social capital might also increase the risk of bullying. Especially a high degree of bonding social capital may increase the risk of bullying through exclusion of members of the group (team/department/organization) that do not conform with rigid group norms. High levels of bonding social capital may result in the group closing in on it self and developing a sense of opposition to others. Norm violations in such groups can lead to sanctions towards the individual member, for example exclusion from the group, because she/he threatens the order of the group [43]. Low individual-level social capital can thus be interpreted as an expression of exclusion from a group. Among actions that can be characterised as bullying, social isolation and exclusion from the community are among those that are considered most violating [49].

Third, causality might also be reversed or reciprocal, such that bullying also degrades the organizational social capital, as targets (and possibly observers) may lose their confidence and trust in coworkers and managers as well as the organization's ability to manage negative acts and injustices. A study on social workers showed that it was hard for them to align their personal experiences with bullying in the workplace to the principles and values they associate their work with, and this made them view their workplaces as hypocritical [48]. Bullying in itself can be viewed as a stressor and a violation of trust $[50,51]$. Trust violations in the workplace can be interpreted as violations of the psychological contract between employer and employee and lead to perceptions of injustice among both targets and observers according to the social exchange perspective [51], thereby undermining the organization's social capital.

In sum, workplace bullying is a serious stressor with devastating short- and long-term consequences for both the individual target, co-workers that observe the bullying and for the organization as a whole. Prevention of bullying and gaining knowledge about the causes and mechanisms behind bullying are important steps toward this end. Other studies have shown bullying to be associated with elements related to social capital, such as a poor social climate, poor communication, low trust and inclusiveness, low cooperation and injustice, high levels of interpersonal conflicts in the organization and professional and value conflicts [25, 26, 28, 29]. However, the literature on workplace or organizational social capital 
is limited due to variations in definitions and understandings of social capital [37]. There is also a lack of empirical research on the consequences of low social capital in relation to the work environment in general [35] and to our knowledge there are no prior studies investigating the association of social capital with workplace bullying. However, the concept of social capital, including organizational trust, justice and shared norms of cooperation, seems to be able to provide complementary insights into the bullying process, and in particular the interactional and communicative dynamics at the collective or organizational level. Subsequently, we want to test the following hypotheses:

H1: Low social capital is associated with selflabelled bullying in the workplace.

H1a: Low social capital between a leader and her/his subordinates will be more strongly associated with selflabelled bullying than low social capital between co-workers.

H2: Low social capital is associated with observed bullying in the workplace.

H2a: Low social capital between a leader and her/his subordinates will be more strongly associated with observed bullying than low social capital between co-workers.

\section{Method}

\subsection{Sample}

The present study is based on self-reported survey data from 2010 from the Danish Work Environment Cohort Study (DWECS) collected by the National Research Centre for the Working Environment (NRCWE). The DWECS survey was sent to approximately 30.000 individuals. Some were respondents in a previous wave of the survey (DWECS-2005) and some had been randomly drawn from the social security register in such a way as to ensure representability [68]. The survey contained 62 items on work environment and health. 14.453 (49\%) filled in the questionnaire, among whom 10.605 were employed. The response rate among those employed at the time of administration was 53\%. Respondents were aged between 18 and 59, with a mean of 42.6 years $(\mathrm{SD}=10.9)$; $46.7 \%$ of the respondents were men. More details on selection, the survey program concerning the DWECS cohorts and variables, items and scales can be found in the NRCWE report on the survey [52] or the NRCWE webpage (www.arbejdsmiljoforskning.dk).

For the analyses, a subset of respondents was chosen, based on responses to the items regarding self-labelled bullying and observed bullying in the workplace (see under measures). To ensure focus on the internal relationships (i.e. what goes on between co-workers, employees and employers) in the workplace, those responding "yes" to bullying or observed bullying from a "client/customer/patient/student" were excluded from the analyses. This left a final dataset of 10.037 respondents, aged 18-59 (mean $=42,7, \mathrm{SD}=10,9), 46,1 \%$ men and 53,9\% women who had either responded "no", "yes, from a co-worker", "yes, from a manager" or "yes, from a subordinate" to the questions on self-labelled and observed bullying.

\subsection{Measures}

\subsubsection{Bullying}

Self-labelled and observed bullying was assessed in two separate items, as follows: "Have you within the last 12 months been exposed to...

- bullying at your workplace (i.e. over several months been exposed to unpleasant or humiliating acts which it has been difficult to defend yourself against)?

- observed that a person has been exposed to bullying?"

Response options to both items were identical and included: "No", "Yes, from colleagues", "Yes, from a manager", "Yes, from subordinates" and "Yes, from clients/customers/patients/students." The two items on bullying in the workplace were dichotomised into the categories "no bullying"/"observed bullying" and "yes, bullying/"observed bullying." The last category contained the following response categories: "Yes, from colleagues", "Yes, from a manager" or "Yes, from subordinates." The item on bullying in this study represents a measuring approach referred to as the self-labelling method [53], which is typically perceived as having high face validity. Furthermore this approach may also have high construct validity if, as is the case in the present study, respondents are presented with a precise, easily understood definition of the concept of bullying [54]. 


\subsubsection{Social capital}

Social capital (Cronbach's alpha $=0.78$ ) was measured with a scale of 9 items. The first six items referred to the respondent and his/her co-workers experiences of trust between management and employees, justice, support and respect, for example: "We have trust in management" and "In general, we are treated with fairness in the workplace". The last three items referred to the respondent's experiences concerning his/her closest co-workers, for example: "We help each other obtain the best possible result." In the analyses the full scale was divided into two minor scales, on the basis of a factor analysis, concerning vertical social capital (relations between manager and employees; Cronbach's alpha $=0.89$ ) and horizontal social capital (relations among co-workers; Cronbach's alpha $=0.92$ ). The 6-point response scale varied from "To a very high degree" to "To a very low degree" and included a "Not relevant" response option. If the respondent answered "To a very high degree", this corresponded to a value of 100 while the answer "To a very low degree" received the value 0 . A high value meant that the respondent experienced a high level of social capital, while a low value corresponded to a low level of social capital. The scales on social capital were developed by researchers from the NRCWE and were validated as part of the descriptive data-analyses from the study presented on-line in Danish [52]. The face validity of the scales seems acceptable as the scales include items on the central elements of organizational social capital (trust, justice, collaboration), encompasses both structural and cognitive elements and is worded with focus on an evaluation of the collective experience in the workplace (for example: "We are..", "We have...").

Responses on the two scales on social capital (vertical and horizontal) were divided into three groups of high, medium and low levels, based on the tertiles of the distribution of responses. We also conducted logistic regressions with the continuous social capital scales as independent variables (data not shown), which produced similar patterns as the present results.

\subsubsection{Sociodemographic variables and covariates}

The analyses were adjusted for sociodemographic variables (age, gender, and seniority), work environment (predictability, work load, work pressure and job influence) and work-related self-efficacy. The selection of covariates was based on theoretical and empirical knowledge of work environment factors that have been associated with stress, low wellbeing or bullying in particular. The scale on predictability was chosen because it included items related to role stress and ambiguity, which has consistently been strongly associated with workplace bullying [55]. The scales on workload, work pressure and influence were included as they together fall in line with the job demand-control model of stress [56] and the notion that occupational stress may increase the risk of conflict and bullying [19]. Separately workload and work/time pressure have been associated with bullying in more recent studies [26, 55]. Work-related self-efficacy was selected because it referred to the individual's perception of her/his own ability, skills and opportunities to act in and affect different circumstances in her/his work. Although the literature on individual antecedents of bulling is varied, ambiguous and relates to many issues [47], it has been argued that victimization is more likely to occur, if the target is low in areas such as self-esteem and self-assertion. Such individuals may be less likely to be able to defend themselves and more likely to produce and escalate conflicts because of their own behaviour [47]. The covariates predictability, workload, work pressure and influence were based on full or partial scales from the validated questionnaire COPSOQ-II [36], while the scale on work-related self-efficacy was inspired by Bandura and Schwarzer's scale on general self-efficacy [57]. Scores on all scales were standardized from $0-100$, with 100 indicating the highest value of each scale in line with usual practice regarding COPSOQ scales.

The scale on predictability (Cronbach's alpha $=0.79$ ) included 2 items, for example: "To what extent do you get all the information you need to do your work well?" Answers were based on a 6point response scale that varied from "To a very high degree" to "To a very low degree".

Work load (Cronbach's alpha $=0.86)$ was measured by three items, for example "How often is it necessary to work overtime?", with the following response options: "Always", "Often", "Sometimes", "Rarely", "Never/Almost never". Work pressure was measured with a single item: "How often is it necessary to work very fast?" Response options to this scale were similar to the scale on work load.

The scale on influence (Cronbach's alpha $=0.72$ ) included 2 items: "Are you involved in the planning of your own work? (For example, how to do it, or who to work with)" and "How often do you have a major influence on decisions about your work?" Response options to the first question were "Always", "Usually", "Usually not" and "Never". 
The three items on work-related self-efficacy (Cronbach's alpha $=0.79$ ) were adapted to a workrelated context by researchers from NRCWE [52]. Response options to the items, for example: "I am confident that I can handle unexpected events in my work", referred to the extent to which respondents felt that the statements characterized themselves. The respondents could thus answer 'Not at all', 'Fits a bit', 'Fits fairly well' or 'Fits exactly'.

\subsection{Statistical analysis}

Cross tables were produced to show how cases of self-labelled bullying and observed bullying respectively were related to levels of social capital (full scale). Logistic regression analyses were then performed to test the hypotheses in three steps using IBM SPSS version 19. In the first step, self-labelled bullying or observed bullying was entered as the dependent variable with social capital (full scale), vertical social capital or horizontal social capital as independent variables. The second step was adjusted for sociodemographic variables (age, gender, seniority), while the third step was further adjusted for self-labelled bullying (in the analyses on witnessed bullying), work environment variables and work-related self-efficacy. We applied logistic regressions and calculated adjusted odds ratios (OR) and 95\% confidence intervals (CI) for the association between bullying and social capital.

\section{Results}

\subsection{Descriptive statistics}

Among the respondents 3\% (304 persons) responded that they had experienced bullying from a co-worker within the last year, 2.4\% (238 persons) had experienced bullying from a manager and $0.4 \%$ ( 44 persons) had experienced bullying from a subordinate. In all, 5.8\% (586 persons) had experienced bullying in the workplace. Among those having observed bullying in the workplace, $11.3 \%$ $(n=1.138)$ responded having observed an employee being bullied by his/her co-workers, 3.5\% $(n=345)$ had observed bullying from a manager against a subordinate and $0.8 \%(n=79)$ had observed a manager being bullied by his/her subordinate. In all, $15.6 \%$ $(n=1562)$ had observed the bullying of a manager or colleague in the workplace. The descriptives of
Table 1

Descriptives of dependent and independent variables for the total study population

\begin{tabular}{lcccc}
\hline Variable & $\mathrm{N}$ & $\%$ & Mean & (SD) \\
\hline Age (years) & 10037 & - & 42.7 & 10.9 \\
Gender & & & & \\
$\quad$ - Women & 5413 & 53.9 & - & - \\
$\quad$ - Men & 4624 & 46.1 & & \\
Self-reported bullying & & & - & - \\
$\quad$ - Yes (total) & 586 & 5.8 & & \\
$\quad$ - Yes, from coworkers & 304 & 3.0 & & \\
- Yes, from a manager & 238 & 2.4 & & \\
$\quad$ - Yes, from subordinates & 44 & 0.4 & & \\
- No & 9270 & 92.4 & & \\
$\quad$ - Missing & 181 & 1.8 & & \\
Observed bullying & & & & \\
$\quad$ - Yes (total) & 1562 & 15.5 & - & - \\
$\quad$ - Yes, from coworkers & 1138 & 11.3 & & \\
$\quad$ - Yes, from a manager & 345 & 3.4 & & \\
- Yes, from subordinates & 79 & 0.8 & & \\
$\quad$ - No & 8140 & 81.1 & & \\
$\quad$ - Missing & 335 & 3.4 & & \\
Vertical social capital scale (0-100) & 9322 & 92.9 & 65.6 & 18.7 \\
Horizontal social capital scale (0-100) & 9411 & 93.8 & 75.5 & 18.0 \\
Seniority (years) & 9067 & 90.3 & 9.5 & 9.2 \\
Work pressure scale (0-100) & 9877 & 98.4 & 54.1 & 2.9 \\
Workload scale (0-100) & 9904 & 98.7 & 44.3 & 20.1 \\
\hline
\end{tabular}

all study variables for the total study population are summarized in Table 1.

\subsection{Logistic regression analyses}

\subsubsection{Self-labelled bullying}

Table 2 shows the results from the logistic regression analyses with self-labelled bullying as outcome. Low levels of horizontal and vertical social capital were consistently related to self-labelled bullying. Including sex, age and seniority variables in the analyses had no impact on the association, while adjustment for work environment and work-related self-efficacy attenuated the associations (horizontal social capital: Odds Ratio $(\mathrm{OR})=3.17$; $C I=2.41-4.18$; vertical social capital: $(O R)=3.25$; $\mathrm{CI}=2.34-4.51$ ). Medium levels of vertical and horizontal social capital were also associated with self-labelled bullying, when compared to high levels of social capital, although significance levels decreased.

\subsubsection{Observed bullying}

Table 3 shows the results from the logistic regression analyses with observed bullying as outcome. Low levels of horizontal and vertical social capital were consistently related to observed bullying. Including sex, age and seniority variables in the 
Table 2

Odds ratios and confidence intervals from logistic regression analyses with self-labelled bullying as dependent variable

\begin{tabular}{|c|c|c|c|c|c|c|}
\hline & Step $1^{\mathrm{c}}$ & & Step $2^{\mathrm{d}}$ & & Step $3^{\mathrm{e}}$ & \\
\hline Independent variables ${ }^{\mathrm{a}, \mathrm{b}}$ & Odds ratio & CI $95 \%$ & Odds ratio & CI $95 \%$ & Odds ratio & CI $95 \%$ \\
\hline \multicolumn{7}{|l|}{ Social capital (vertical) } \\
\hline Low & $6.98^{* * *}$ & $5.30-9.20$ & $7.01^{* * *}$ & $5.32-9.25$ & $3.25^{* * *}$ & $2.34-4.51$ \\
\hline Medium & $2.26^{* * *}$ & $1.67-3.06$ & $2.27^{* * *}$ & $1.68-3.08$ & $1.59^{* *}$ & $1.16-2.18$ \\
\hline \multicolumn{7}{|l|}{ Social capital (horizontal) } \\
\hline Low & $5.06^{* * *}$ & $3.89-6.59$ & $5.06^{* * *}$ & $3.88-6.60$ & $3.17^{* * *}$ & $2.41-4.18$ \\
\hline Medium & $1.48^{*}$ & $1.10-2.00$ & $1.50^{*}$ & $1.11-2.02$ & 1.23 n.s. & $0.90-1.66$ \\
\hline
\end{tabular}

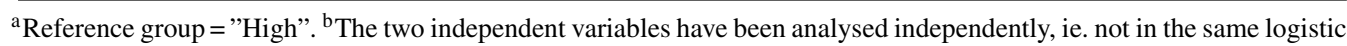
regressions. ${ }^{\mathrm{c}}$ Includes the stated social capital variable. ${ }^{\mathrm{d}}$ Further includes age, sex and seniority. ${ }^{\mathrm{e}}$ Further includes work environment variables and work-related self-efficacy. ${ }^{*} p<0.05 ;{ }^{* *} p<0.01 ;{ }^{* * *} p<0.001$.

analyses had no impact on the association, while adjustment for work environment and work-related self-efficacy attenuated the associations (horizontal social capital: $(\mathrm{OR})=1.60 ; \mathrm{CI}=1.35-1.89$; vertical social capital: $(\mathrm{OR})=2.09 ; \mathrm{CI}=1.70-2.56)$. Medium levels of vertical and horizontal social capital variables were also associated with observed bullying, when compared to high levels of social capital, although significance levels decreased.

\section{Discussion}

All hypotheses were confirmed in the analyses. The results showed that low social capital was related to a highly increased likelihood of self-labelled bullying, and to a somewhat increased likelihood of observed bullying. Lower levels of social capital between employees and managers (vertical) were more closely associated with observed bullying than social capital among employees (horizontal). However, the difference between the two variables was minimal and insignificant in relation to targets of bullying. Finally, results showed that factors related to the work environment and personality partly explained the associations between social capital on the one hand and self-reported and observed bullying on the other hand.

This study supports Leymann's work environment hypothesis $[18,19]$ which proposes that characteristics of the psychosocial work environment are of particular importance in the development of bullying in the workplace. The present study especially supports and adds to previous research on the work environment hypothesis which focuses on features related to organizational climate and culture $[17,58]$. Both quantitative and qualitative studies have shown associations between bullying in the workplace and a poor social climate, poor communication, low trust and inclusiveness, as well as experiences of low cooperation and injustice, high levels of interpersonal conflicts and professional and value conflicts $[25,26$, 28,29 ]. Recently, Kiss et al. [30] explored the associations between organizational social capital and the presence of "gossip and slander", "conflicts and quarrels", sick leave prevalence and prevalence of poor working ability. They found significant associations between organizational social capital and "gossip and slander", sick leave and poor working ability at both the individual and group level. The present study adds to these results by showing that low self-reported social capital highly increased the likelihood of selflabelled and observed bullying, even after adjustment for work environment features such as predictability, work load, work pressure and job influence.

Research has shown that both targets and observers of bullying report more negative work environments than non-target, non-observer respondents [21, 25]. Furthermore, both targets of bullying and non-targets experience adverse working conditions in groups where bullying takes place, especially with regards to relational (social climate, leadership behaviour and role demands) rather than task-related elements of the psychosocial work environment [22]. This is also the case in our study, where both targets and observers report lower levels of social capital than non-targets and non-observers. One of the major limitations of this study regards the design. The analyses were based on individual-level, self-report questionnaire data, without the possibility of aggregating data at workplace level. As such we have a limited comprehension of the organizational social capital at the workplaces in which the respondents work. It may be speculated that workplace bullying is inevitably rare if social capital is high. As the results of the present study are based on individual-level analyses of crosssectional data, we cannot say for sure, that this is or is not the case. Other studies, however, have shown that 
Table 3

Odds ratios and confidence intervals from logistic regression analyses with observed bullying as dependent variable

\begin{tabular}{|c|c|c|c|c|c|c|}
\hline \multirow[b]{2}{*}{ Independent variables ${ }^{a b}$} & \multicolumn{2}{|c|}{ Step $1^{\mathrm{c}}$} & \multicolumn{2}{|c|}{ Step $2^{\mathrm{d}}$} & \multicolumn{2}{|c|}{ Step $3^{\mathrm{e}}$} \\
\hline & Odds ratio & CI 95\% & Odds ratio & CI 95\% & Odds ratio & CI $95 \%$ \\
\hline \multicolumn{7}{|l|}{ Social capital (vertical) } \\
\hline Low & $3.59^{* * *}$ & $3.07-4.20$ & $3.57^{* * *}$ & $3.05-4.17$ & $2.09^{* * *}$ & $1.70-2.56$ \\
\hline Medium & $1.89^{* * *}$ & $1.60-2.21$ & $1.88^{* * *}$ & $1.60-2.21$ & $1.53^{* * *}$ & $1.28-1.82$ \\
\hline \multicolumn{7}{|l|}{ Social capital (horizontal) } \\
\hline Low & $2.54^{* * *}$ & $2.18-2.96$ & $2.51^{* * *}$ & $2.16-2.93$ & $1.60^{* * *}$ & $1.35-1.89$ \\
\hline Medium & $1.28^{* *}$ & $1.10-1.50$ & $1.27^{* *}$ & $1.08-1.49$ & 1.10 n.s. & $0.93-1.30$ \\
\hline
\end{tabular}

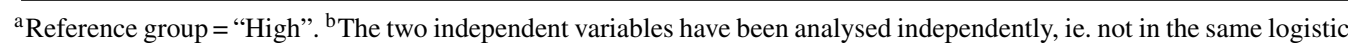
regressions. ${ }^{\mathrm{c} I n c l u d e s}$ the stated social capital variable. ${ }^{\mathrm{d}}$ Further includes age, sex and seniority. ${ }^{\mathrm{e}}$ Further includes selflabelled bullying, work environment variables and work-related self-efficacy. ${ }^{*} p<0.05 ;{ }^{* *} p<0.01 ;{ }^{* * *} p<0.001$.

the impact of social capital on different outcomes may differ according to level of analysis. In a Finish study low individual-level social capital (but not aggregate workplace-level social capital) was associated with self-reported depression [39]. Individual-level social capital has been shown to be associated with exposure to "gossip and slandering" in the workplace [30] and impairment of self-rated health [40] to a higher degree than workplace-level social capital. Studies on community- and country-level social capital have shown that the effect of social capital, in certain circumstances, provides benefits for one population, but not for another $[59,60]$. One multilevel study analyzing on country-level and individual level social capital (using "trust" as an indicator of social capital), showed strong cross-level interactions between the two levels [61]. The study also suggested that high contextual (or group-level) trust may have a negative impact on the self-rated health of individuals reporting low interpersonal trust. In sum, previous research including multi-level, and especially cross-level, analyses on the impact of social capital, suggest complex cross-level dynamics. This highlights the notion of social capital as a multilevel perspective encompassing the nested levels of organizational entities [62]. Furthermore these studies draw attention to the understanding that social capital can have alternative meanings, antecedents and consequences at different levels [63].

In relation to workplace bullying, a number of studies have investigated the work environment hypothesis in multilevel analyses. These showed that a poor work environment is a common feature within workplaces and workgroups, where bullying takes place [22, 64]. These studies have primarily been aimed at documenting that the poor work environment self-ratings from prior individual-level analyses, did not merely reflect the eyes of the beholder (ie. the targets of bullying). We do not argue against these studies. Rather we suggest, like others (for example Hauge [65]), that future studies should include multiple levels of analysis and their potential cross-level interaction. Furthermore, we suggest that the concept of social capital seems especially relevant in relation to workplace bullying, because of it's multilevel potential of encompassing the nested levels of the organization, the workgroup and the individual employee. Workplace bullying is generally considered a complex phenomenon, impacted by individual as well as various workplace levels and structures, with potential negative consequences for both individuals and organizations [1]. Hence, we suggest that a multilevel theoretical framework such as social capital, may provide new insights into the development of workplace bullying. This may also prove valuable in the development of interventions directed at preventing and managing workplace bullying. As such, the present study specifically proves it's value in establishing social capital as a potent concept in relation to workplace bullying. Even if, for a starter, on an individual level of analysis.

\subsection{Methodological considerations}

The study has several strengths. It is based on a large, representative sample of the Danish working population. Analyses were based on responses from both self-labelled targets and observers of bullying in the workplace, thereby extending the findings of associations between organizational social capital and bullying in the workplace beyond the subjective experience of the target of bullying. Also, this study is, to our knowledge, the first to explore the association between the construct of vertical and horizontal organizational social capital and bullying in the workplace.

Several limitations must also be mentioned. First, the study is based on data from a cross-sectional, 
self-report survey which limits inferences on causality and particularly reverse causality is an issue in the present study. The study design furthermore limits internal validity and increases the possibility that mono method bias or unmeasured third variables are present. Second, a source of concern regarding the validity of the findings comes from the fairly low response rate $(53 \%)$ in the form of potential selection bias. However, researchers at the NRCWE conducted additional analysis of the non-responders to the survey, and found that although response rates varied with regard to gender, age, job group and geographical location, this did not affect the descriptive analyses in any significant ways [52]. Also the prevalence of bullying in the present study lies within the range of prevalence rates found in other comparable studies [47]. This suggests that selection bias, although present, does not pose a significant bias to the results. Third, the analyses were conducted at the individual level which limits the statistical conclusion potentials [66]. This also has consequences for the validity of the study, as we were not able to aggregate data on social capital at the workplace-level, which is typically recommended [30, 62]. However, as mentioned before, the study includes analyses based on responses from both targets of bullying and observers of bullying and thus, to some extent, may illustrate that experiences of low social capital to some degree may apply to the workgroup and not just the individual targets. Fourth, unlike many definitions and operationalisations of bullying, the operationalisation in this study does not emphasize the frequency of the actions (daily, weekly, monthly etc.) and lacks information of the source of bullying. This is a limitation because many different experiences of bullying are grouped together, even though the nature and consequences of the experiences may be qualitatively different [67]. Fifth, bullying was dichotomized into yes/no categories, although it might be suspected that vertical and horizontal social capital are differently associated with bullying from a manager and bullying from a co-worker. However, this question is beyond the scope of the present study. Finally, it can also be argued that more or other covariates, for example role conflicts, ambiguity, job insecurity and leadership styles, as well as possible interaction effects, could have been included in the analyses [21]. However, the choice of covariates included central factors related to Karasek's [56] job demand-control model (work load, work pressure and influence) as well as a personality factor (work-related self-efficacy). It was not possible to include role conflicts and demands (a well-studied risk factor associated with bullying), as these were not measured in the survey. The items in the predictability scale however, included items related to whether the respondent perceived having been informed of decisions and changes that might affect his/her work. This is in line with Matthiessen \& Einarsen's [46] operationalization of role stress as unclear and conflicting expectations regarding the tasks and the daily work. Furthermore we chose not to include social support and rewards to the analyses as these are conceptually close to the concept of social capital, and may have posed a risk of over-control and collinearity [68].

\section{Conclusion}

In this study we found significant associations between organizational social capital and bullying in the workplace. The results show that selfreported experiences of low vertical and horizontal workplace social capital are associated with a significantly increased likelihood of both self-labelled and observed bullying in the workplace. Due to methodological limitations, it is not possible to say whether low social capital is a causal factor in the development of bullying or vice versa, but it is likely that the causality is bi-directional. The results may however suggest that preventive efforts toward bullying may be more efficient if combined with improvements of the social capital at the workplace. Further studies should explore the relative importance of the different aspects of organizational social capital and the causal relations between organizational social capital and bullying in the workplace, as well as focusing on multilevel analyses, including the individual, workgroup, department and organization.

\section{Acknowledgments}

We would like to thank the employees at the National Research Centre for the Working Environment for their help and assistance in providing the data for the present analyses.

The present study was conducted as part of the first author's master thesis in psychology and the NRCWE generously shared the data for this purpose.

\section{Conflict of interest}

None to report. 


\section{References}

[1] Branch S, Ramsay S, Barker M. Workplace bullying, mobbing and general harassment: A review. International Journal of Management Reviews 2013;15(3):280-99.

[2] The Working Environment Act. 2010. Available at: https:// www.retsinformation.dk/forms/r0710.aspx?id=133159. Accessed December 14, 2016.

[3] Ordinance on the performance of work. 2004. Available at: https://arbejdstilsynet.dk/da/regler/bekendtgorelser/a/samarbejdets-udforelse-559. Accessed December 14, 2016.

[4] Danish Work Environment Authority. Mobning og seksuel chikane. 2016; Available at: http://arbejdstilsynet. $\mathrm{dk} / \mathrm{da} /$ regler/at-vejledninger/m/d-4-2-mobning-og-seksuelchikane. Accessed December 14, 2016.

[5] Hogh A, Hansen ÅM, Mikkelsen EG, Persson R. Exposure to negative acts at work, psychological stress reactions and physiological stress response. J Psychosom Res 2012;73(1):47-52.

[6] Hansen ÅM, Hogh A, Garde AH, Persson R. Workplace bullying and sleep difficulties: A 2-year follow-up study. Int Arch Occup Environ Health 2014;87(3):285-94.

[7] Notelaers G, Einarsen S, De Witte H, Vermunt JK. Measuring exposure to bullying at work: The validity and advantages of the latent class cluster approach. Work \& Stress 2006;20(4):289-302.

[8] Einarsen S, Nielsen MB. Workplace bullying as an antecedent of mental health problems: A five-year prospective and representative study. Int Arch Occup Environ Health 2015;88(2):131-42.

[9] Kivimaki M, Virtanen M, Vartia M, Elovainio M, Vahtera J, Keltikangas-Jarvinen L. Workplace bullying and the risk of cardiovascular disease and depression. Occup Environ Med 2003;60(10):779-83.

[10] Gullander M, Hogh A, Hansen AM, Persson R, Rugulies R, Kolstad HA, et al. Exposure to workplace bullying and risk of depression. J Occup Environ Med 2014;56(12):1258-65.

[11] Nielsen MB, Tangen T, Idsoe T, Matthiesen SB, Magerøy N. Post-traumatic stress disorder as a consequence of bullying at work and at school. A literature review and meta-analysis. Aggression and Violent Behavior 2015;21:17-24.

[12] Hogh A, Henriksson ME, Burr H. A 5-year follow-up study of aggression at work and psychological health. Int J Behav Med 2005;12(4):256-65.

[13] Ortega A, Christensen KB, Hogh A, Rugulies R, Borg $\mathrm{V}$. One-year prospective study on the effect of workplace bullying on long-term sickness absence. J Nurs Manag 2011;19(6):752-9.

[14] Svedberg P, Alexanderson K. Associations between sickness absence and harassment, threats, violence, or discrimination: A cross-sectional study of the Swedish Police. Work 2012;42(1):83-92.

[15] Glambek M, Skogstad A, Einarsen S. Take it or leave: A fiveyear prospective study of workplace bullying and indicators of expulsion in working life. Ind Health 2015;53(2):160-70.

[16] Salin D. Ways of explaining workplace bullying: A review of enabling, motivating and precipitating structures and processes in the work environment. Human Relations 2003; 56(10):1213-32.

[17] Salin D, Hoel H, Einarsen S, Hoel H, Zapf D, Cooper C. Organisational causes of workplace bullying. Bullying and Harassment in the Workplace: Developments in Theory, Research, and Practice 2011:227-43.

[18] Leymann H. Mobbing and psychological terror at workplaces. Violence Vict 1990;5(2):119-26.
[19] Leymann H. The content and development of mobbing at work. European Journal of Work and Organizational Psychology 1996;5(2):165-84.

[20] Balducci C, Cecchin M, Fraccaroli F. The impact of role stressors on workplace bullying in both victims and perpetrators, controlling for personal vulnerability factors: A longitudinal analysis. Work \& Stress 2012;26(3):195-212.

[21] Johan Hauge L, Skogstad A, Einarsen S. Relationships between stressful work environments and bullying: Results of a large representative study. Work \& Stress 2007;21(3):220-42.

[22] Skogstad A, Torsheim T, Einarsen S, Hauge LJ. Testing the work environment hypothesis of bullying on a group level of analysis: Psychosocial factors as precursors of observed workplace bullying. Appl Psychol 2011;60(3):475-95.

[23] Hoel H, Glas $\varnothing$ L, Hetland J, Cooper CL, Einarsen S. Leadership styles as predictors of self-reported and observed workplace bullying. Br J Manage 2010;21(2):453-68.

[24] Skogstad A, Einarsen S, Torsheim T, Aasland MS, Hetland $\mathrm{H}$. The destructiveness of laissez-faire leadership behavior. J Occup Health Psychol 2007;12(1):80.

[25] Vartia M. The sources of bullying-psychological work environment and organizational climate. European Journal of Work and Organizational Psychology 1996;5(2):203-14.

[26] Baillien E, Neyens I, De Witte H. Organizational, team related and job related risk factors for workplace bullying, voilence and sexual harassment in the workplace: A qualitative study. International Journal of Organisational Behaviour 2008;13(2):132-46.

[27] Salin D. Risk factors of workplace bullying for men and women: The role of the psychosocial and physical work environment. Scand J Psychol 2015;56(1):69-77.

[28] Høgh A, Hansen ÅM, Bloch C, Mikkelsen EG, Maier C, Persson R, et al. Mobning og negativ adfærd på arbejdspladsen. : Det Nationale Forskningscenter for Arbejdsmiljø København, 2009.

[29] Strandmark M, Hallberg L. Being rejected and expelled from the workplace: Experiences of bullying in the public service sector. Qualitative Research in Psychology 2007;4(1-2):1-14.

[30] Kiss P, De Meester M, Kristensen TS, Braeckman L. Relationships of organizational social capital with the presence of "gossip and slander,"“quarrels and conflicts," sick leave, and poor work ability in nursing homes. Int Arch Occup Environ Health 2014;87(8):929-36.

[31] Kristensen T. A questionnaire is more than a questionnaire. Scand J Public Health 2010;38(3):149.

[32] Pierre B. The Forms of Social Capital. In: Richardson JG, editor. Handbook of Theory and Research for the Sociology of Education Westport, CT.: Greenwood Press, 1986. pp. 241-58.

[33] Putnam RD, Leonardi R, Nanetti RY. Making democracy work: Civic traditions in modern Italy. : Princeton university press, 1994

[34] Leana CR, Van Buren HJ. Organizational social capital and employment practices. Academy of Management Review 1999;24(3):538-55.

[35] Olsen KG, Thoft E, Hasle P, Kristensen T. Virksomhedens sociale kapital-en hvidbog. København: Arbejdsmiljørådet 2008.

[36] Pejtersen JH, Kristensen TS, Borg V, Bjorner JB. The second version of the Copenhagen Psychosocial Questionnaire. Scand J Public Health 2010;38(Suppl 3):8-24.

[37] Sabatini F. Social capital as social networks: A new framework for measurement and an empirical analysis of its 
determinants and consequences. The Journal of SocioEconomics 2009;38(3):429-42.

[38] Hasle P, Møller N. From conflict to shared development: Social capital in a tayloristic environment. Economic and Industrial Democracy 2007;28(3):401-29.

[39] Kouvonen A, Oksanen T, Vahtera J, Stafford M, Wilkinson $\mathrm{R}$, Schneider J, et al. Low workplace social capital as a predictor of depression: The Finnish Public Sector Study. Am J Epidemiol 2008;167(10):1143-51.

[40] Oksanen T, Kouvonen A, Kivimäki M, Pentti J, Virtanen M, Linna A, et al. Social capital at work as a predictor of employee health: Multilevel evidence from work units in Finland. Soc Sci Med 2008;66(3):637-49.

[41] Tsuboya T, Tsutsumi A, Kawachi I. Change in psychological distress following change in workplace social capital: Results from the panel surveys of the J-HOPE study. Occup Environ Med 2015;72(3):188-94.

[42] Svendsen GT, Svendsen GLH. Social kapital: En introduktion. : Hans Reitzel; 2006.

[43] Hasle P, Thoft E, Olesen KG. Ledelse med social kapital. : L\&R Business, 2010.

[44] Purpora C, Blegen MA, Stotts NA. Hospital staff registered nurses' perception of horizontal violence, peer relationships, and the quality and safety of patient care. Work 2015;51(1):29-37.

[45] Snyder JA, Scherer HL, Fisher BS. Social organization and social ties: Their effects on sexual harassment victimization in the workplace. Work 2012;42(1):137-50.

[46] Matthiesen SB, Einarsen S. Perpetrators and targets of bullying at work: Role stress and individual differences. Violence Vict 2007;22(6):735-53.

[47] Zapf D, Einarsen S. Individual antecedents of bullying: Victims and perpetrators. Bullying and Harassment in the Workplace: Developments in Theory, Research, and Practice 2011:177-200.

[48] Whitaker T. Social workers and workplace bullying: Perceptions, responses and implications. Work 2012;42(1):115-23.

[49] Escartín J, Rodríguez-Carballeira A, Zapf D, Porrúa C, Martín-Peña J. Perceived severity of various bullying behaviours at work and the relevance of exposure to bullying. Work \& Stress 2009;23(3):191-205.

[50] Giorgi G. Workplace bullying in academia creates a negative work environment. An Italian study. Employee Responsibilities and Rights Journal 2012;24(4):261-75.

[51] Parzefall M, Salin DM. Perceptions of and reactions to workplace bullying: A social exchange perspective. Human Relations 2010;63(6):761-80.

[52] Arbejdsmiljø og helbred i Danmark 2010. Resumé og resultater. 2011.

[53] Nielsen MB, Matthiesen SB, Einarsen S. The impact of methodological moderators on prevalence rates of workplace bullying. A meta-analysis. J Occup Organ Psychol 2010;83(4):955-79.

[54] Nielsen MB, Notelaers G, Einarsen S. Measuring exposure to workplace bullying. Bullying and Harassment in the Workplace: Developments in Theory, Research, and Practice 2011;2:149-74.

[55] Bowling NA, Beehr TA. Workplace harassment from the victim's perspective: A theoretical model and meta-analysis. J Appl Psychol 2006;91(5):998.

[56] Karasek Jr RA. Job demands, job decision latitude, and mental strain: Implications for job redesign. Adm Sci Q 1979:285-308.

[57] Bandura A, Schwarzer R. Self-efficacy: Thought control of action. Washington: Hemisphere, 1992.

[58] O'Farrell C, Nordstrom CR. Workplace bullying: Examining self-monitoring and organizational culture. Journal of Psychological Issues in Organizational Culture 2013;3(4): 6-17.

[59] Mitchell CU, LaGory M. Social capital and mental distress in an impoverished community. City and Community 2002;1(2):199-222.

[60] Murayama H, Fujiwara Y, Kawachi I. Social capital and health: A review of prospective multilevel studies. Journal of Epidemiology 2012;22(3):179-87.

[61] Campos-Matos I, Subramanian SV, Kawachi I. The "dark side' of social capital: Trust and self-rated health in European countries. Eur J Public Health 2016;26(1):90-5.

[62] Payne GT, Moore CB, Griffis SE, Autry CW. Multilevel challenges and opportunities in social capital research. Journal of Management 2011;37(2):491-520.

[63] Adler PS, Kwon S. Social capital: Prospects for a new concept. Academy of Management Review 2002;27(1):17-40.

[64] Hauge LJ, Skogstad A, Einarsen S. Role stressors and exposure to workplace bullying: Causes or consequences of what and why? European Journal of Work and Organizational Psychology 2011;20(5):610-30.

[65] Hauge LJ. Environmental antecedents of workplace bullying: A multi-design approach. 2010.

[66] Neall AM, Tuckey MR. A methodological review of research on the antecedents and consequences of workplace harassment. J Occup Organ Psychol 2014;87(2):225-57.

[67] Lutgen-Sandvik P, Tracy SJ, Alberts JK. Burned by bullying in the American workplace: Prevalence, perception, degree and impact. Journal of Management Studies 2007;44(6):837-62.

[68] Kreiner S. Logistisk regression. Statistisk problemløsning. Præmisser, teknik og analyse. (Logistic regression. Statistical problemsolving. Premises, technique and analysis. Djøf/Danish Association of lawyers and economists) 1999;415-534. 